\section{Drug Antagonism}

SIR,-In treating a lady aged 77 years with L-dopa for a long standing Parkinsonism, was delighted with the results. Three months later, however, when the patient was on dosage of $500 \mathrm{mg}$ four times daily, I had occasion to put the patient on chlordiazepoxide (Librium) in a dose of $10 \mathrm{mg}$ three times daily. To my amazement she regressed within 24 hours to her original Parkinsonian state. The L-dopa was being continued at the time. As the only significant factor was the exposure of the patient to chlordiazepoxide, I stopped that drug. Within 36 hour her progress was back to her previous state.

Since then I have come across othe patients who have been tried on L-dopa but it has failed to have an effect on the disease. Two of these had a definite history of having been on chlordiazepoxide or a combination drug at the time. I wonder how many "failed L-dopa" cases there are in Britain because of chlordiazepoxide or combinations of this drug.-I am, etc.,

Oldmeldrum,

LEWIS MACKIE Aberdeenshire

\section{Halothane Hepatitis}

SIR,-The current attack and defence of halothane in relation to liver toxicity by $\mathrm{Dr}$. P. Sharpstone and others (20 February, p 448) and Dr. T. H. S. Burns and Dr. M. W Johnstone (29 May, p. 523) could lead, if you will allow it, to another generation of debate on the question of which is better for the patient: (1) one toxic drug which will produce all or nothing that the surgeon requires from anaesthesia, or (2) a multitude of drugs which can be given in non-toxic dosage to produce any or all of the facets of anaesthesia as required by the surgical conditions.

I am voicing no new thought but merely re-stating the opinions of very many authors during the last 25 years, too numerous to quote references in a short letter.

My opinion favours the multidrug technique-namely, induction by intravenous short-acting barbiturate, maintenance of sleep by unpolluted nitrous oxide and oxygen, intravenous analgesics as required, and manual assistance of respiration in the non- or partially curarized patient (mechanical in preference to manual ventilation in the fully curarized patient). May I remind readers that the above technique is applicable throughout the whole age scale from neonatal to geriatric patient.

May I also point out to anaesthetists that those who are skilled and experienced in multi-drug techniques are better equipped for work in intensive therapy units than those whose experience has been limited to the administration of a single drug.-I am, etc.,

London $\mathbb{W} . \dot{4}$

Donald Blatchley

\section{Dental Emergencies}

SIR,-The attention of my Committee has been drawn to Appendix VI of the Annual Report of Council on "Gaps in Medical Care" and the item on dental emergencies (Supplement, 8 May, p. 88).

It should be pointed out that with regard to the final paragraph "The agonizing toothache touring London on a Sunday", the dental profession in Inner London have always been willing to provide an emergency service, subject of course to the availability of the necessary facilities such as premises, adequate ancillary staff, and appropriate payment for services.

This is, however, a national problem and when the question of emergency dental treatment has been raised by questions in the House of Commons successive Ministers of Health have stated in their replies that they do not consider that the provision of an emergency service is necessitated by demand. Therefore, until the policy of the Department of Health and Social Security is changed, it does not seem that such a service can be provided.

In any event, the larger hospitals in London have an emergency dental service.I am, etc.,

Ivor DoMB Inner London Local Dental Committee Lundun W.C.1

\section{Atheroma: A New Hypothesis}

SIR,-Correspondence (8 May, p. 335) following your detailed leading article (3 April, p. 2), suggests that there has been incomplete appreciation of some of the observations and arguments in our communication.

We request therefore an opportunity briefly to state some of the salient points and to emphasize certain important conclusions which appear to have been overlooked.

(1) It has proved possible to identify regions in the arterial system which experience relatively high or low wall shear.

(2) A distinction has been made between man and animals on "stable" diets, termed as being in a quasi steady state, and animals in which there has been abrupt marked change of diet, leading to sudden massive alteration of plasma levels of lipid, etc., termed as being in a transient situation.

(3) In man and certain animals in a quasi steady state, early atheromatous lesions have been shown to occur preferentially in regions known to experience low wall shear.

(4) This distribution is inconsistent with the hypothesis of mechanical damage to the arterial wall by the flowing blood; such a hypothesis implies the occurrence of lesions in high shear regions, which are spared in the quasi steady state.

(5) In certain animals studied in a transient situation, the early lesions have been shown to occur preferentially in regions known to experience high wall shear.

(6) It is shown in the communication how the diffusion of material, in either direction between the blood and the arterial wall, may be significantly influenced by wall shear. Shear facilitates diffusion by enhancing the concentration gradient, which drives the diffusion. In the case of diffusion from wall to blood, material which has diffused out is effectively swept away. In the case of diffusion in the reverse direction, shear makes the material more readily available, close to the wall.

(7) If the material composing early atheromatous lesions in man, and in animals in a quasi steady state, were diffusing from the blood to the wall, then it would accumulate preferentially in high shear regions. However, this distribution is not observed, hence such a hypothesis is unacceptable. The distribution of early lesions in man and animals in the quasi steady state is instead consistent with the hypothesis that materials which have been synthesized in the wall are diffusing out from wall to blood. As expected, such diffusional efflux will be inhibited in low shear regions.

(8) The preferential accummulation of material in high shear regions in transient studies, the "mirror-image" of the quasi steady state distribution, is consistent with the diffusion of accumulating materials from blood to wall. The requirement is that the plasma levels of the accumulating material exceed the wall levels.

(9) Concerning the association of atheroma with hypertension, it is possible, as mentioned in the communication, that this is an illustration of the influence of wall shear on diffusion; blood velocity and arterial wall shear will be reduced if there is arterial dilatation associated with the elevation of blood pressure, and a normal flow rate. A similar mechanism might operate in syphilitic aortitis.

We are anxious to draw attention to one other aspect of our communication. We are particularly concerned that the proposed shear dependent mass transfer hypothesis should not be misconstrued as solely invoking wall shear, or haemodynamics, as affecting atherogenesis; the hypothesis links haemodynamics and biochemical factors. The communication points out that the evidence is consistent with wall shear being a major controlling factor in the rate of development of the early stage of the atheromatous process. However, it clearly further argues that the progression of the process will also be retarded by any means which reduces the accumulation of atheromatous material by influencing its rate of net production or diffusion. Manifestly this includes, in addition to wall shear, such local factors as the nature and availability of precursor, the rate of synthesis and degradation or removal of accumulating material, and such overall factors as the transport system for the materials in the body.-We are, etc.,

C. G. CARO

\section{J. M. FITZ-GERALD} R. C. SCHROTER

Physiological Flow Studies Unit,

Imperial College of Science and Technology, London S.W.7

1 Caro, C. G., Fitz-Gerald, J. M., and Schroter, R. C., Proceedings of the Royal Society, Series
$B, 1971,177,109$.

\section{Oestrogens in Oophorectomized Women}

SIR,-One aspect of the treatment of postmenopausal women using oestrogens for replacement therapy has as yet not been discussed in the literature. I have found continuous daily therapy of synthetic oestrogenic compounds similar to those given by Dr. S. Gow and Professor I. MacGillivray (10 April, p. 73) to be unacceptable to most "normal" postmenopausal women-that is those with intact gonads. They develop a variety of clinical symptoms that suggest a cumulative action of the drug. In support of this view, in one patient the eosinophilic vaginal smears persisted six weeks after treatment had ceased. However, there is as yet no satisfactory scientific parameter on which this form of treatment can be based ${ }^{1}$ and additional factors affecting the treatment 